\title{
Studying on the Factors Affecting the Benefit of Agricultural Research Programs
}

\author{
Chunmei Wang
}

\begin{abstract}
Agricultural research and extension programs have been built in most of the world's economies because agricultural science and technology innovation is the source to push agricultural development. Since 2004 China has increased gradually agricultural research investment, which promoted agriculture to develop rapidly. However, China's agricultural research investment has been lagging behind that of developed countries in proportion of investment or benefit of agricultural programs. In this paper, the factors affecting the Benefit of Agricultural research programs are been studied by Principal component analysis. It showed that research management and production factors are majors factors that impacting benefit of agricultural programs. So, the government should build scientific management system of agricultural programs and improve subsidiarity production factors to ensure the benefits of agricultural research projects could be effectively.
\end{abstract}

Index Terms-Agricultural research programs, benefit, factors, principal component analysis.

\section{INTRODUCTION}

Agricultural science and technology innovation is the source to push agricultural development, and the research investment programs are the main method to realize the innovation. The quantity of China's agricultural research programs increased rapidly during the past five decades and China's agricultural research system is now one of the largest public systems in the world. According to the National Strategic Development Plan, the government has targeted to support a variety of agricultural science and technology programs [1]. The goal of most agricultural research programs are to be undertaken research and developed that will ultimately improve the productivity and sustainability of the agricultural and food sector.

The investment to agricultural science and technology programs is the major way supporting agricultural research. Agricultural research investment is the direct and indirect costs of the various research activities to promote agricultural development, and is the basis to guarantee the achievements of agricultural scientific and technological. By this way, the agriculture would develop rapidly by applying the agricultural research achievement with good quality and benefit. Evenson(2000) explained the total factor productivity in agricultural research and extension investment, it showed public investment in agricultural

Manuscript received March 29, 2013; revised June 6, 2013.

Chunmei Wang is with the College of Economics and Management, China Agricultural University, Beijing, P.R. China and College of accounting, Inner Mongolia University of Finance and Economics, Hohhot, P. R. China (e-mail: hannahwcm@foxmail.com). research is a positive impact on agricultural productivity [2]. Other scholars reached the same conclusion.

The government is the main investor in China's agricultural research programs and public agencies in China employ more agricultural scientists than any other public system in the world. Since 2004, China attaches great importance to the development of agricultural science and technology. Till 2012, the ninth No.1 document of CPC Central Committee focused on the problems about Agriculture, Rural areas and Peasantry again, the suggestions about promoting supply of agricultural products by sustainable agricultural science and technology innovation has been clearly proposed. It is showed in this document that agricultural science and technology innovation is the radical method to realize agricultural sustainable and stable development. It would be sure that growth rate of agricultural research investment is higher than that of revenue. Huang jikun and $\mathrm{Hu}$ ruifa have studied systematically the topic of agricultural research investment, and found the funding in agricultural research has been not enough very much. It has influenced directly quantity and quality of agricultural research achievement. China's agricultural research investment experienced slow growth from 1980 to 2000(Huang Jikun, 1998/2003) [3], [4], then it has expanded rapidly since new century. For example, the total government investment of 2005 is twice that of 1991(Hu Farui, 2007) [5]. However, agricultural research expenditures as a percentage of total government expenditures were comparatively low in the past. Agricultural research spending as a share of total national $R \& D$ expenditures has also been quite stable. In contrast, agricultural research expenditures as a percentage of government spending on agriculture increased steadily. Although the quantity of the agricultural expenditures has increased rapidly, the percentage ratio of funds of agricultural research investments is lagging behind the United States and other developed countries. The proportion of Chinese national agricultural research expenditure to the total agricultural output is $1 / 6$ to American proportion. The lack of investment in agricultural research has a negative impact to the needs of farmers in agricultural technology, which reduces the farmers' willingness of adopting the new technologies. Thus, it is difficult to fundamentally realize the industrialization of scientific and technological achievements and to construct the competitiveness of agricultural products.

In the supporting of China's science and technology plan, agricultural science and technology in China has achieved remarkable results. New varieties of high-yield and high-quality plants and animals have been created, and key technologies of producing and processing of agricultural products have been developed. It improves the technical level 
of agriculture prenatal, delivery, postpartum, and promotes technological advances in agriculture. It makes an important contribution for agricultural development, industrial restructuring, nurturing and developing of emerging industries as well as personnel training.

The Ag GDP per person increased dramatically from 13782 yuan to 49450 during $2001-09^{1}$. The farmers' living standard has been greatly improved because of the progress of agricultural research and development. By the end of ten five year plan, the contribution rate of scientific and technological progress to the agricultural growth is $48 \%$. As a developing country for a long time, it is a problem that whether the benefit of Chinese agricultural research investment is well in the current climate of declining funding. We should put focus on the factors that influence the benefit of Chinese agricultural research investment. In this paper, an attempt is made to explore the variables and procedures that may influence the benefit of agricultural research investment.

\section{The Benefit of Agricultural Research Programs AND FACTORS ANALYSIS}

\section{A. The Benefit of Agricultural Research Programs}

Agricultural science administrators and those to whom they answer have been interested in measures of the economic benefits from agricultural R\&D for a long time. Mcmillen (1929) attempted to evaluate US agricultural R\&D firstly. Since then, hundreds of studies have reported measures of the returns to agricultural R\&D. Although a great deal of effort and money has been spent on assessing the impacts of agricultural $\mathrm{R} \& \mathrm{D}$, questions persist about what the resulting evidence means, its accuracy, and how it can be used.

The benefit of agricultural research programs is the return on the agricultural economy development, improving farmers' living standards and labor productivity after the funding of agricultural research has invested. It involves economic, social and ecological benefits of agricultural production systems. There is a time lag that the agricultural research investment has impacts economic growth, and the current and previous investment both influence agricultural economic growth. Julian M.Alston (2000) thought the total benefits are not simply the sum of the anticipated benefits of all the projects. When measuring the returns to the R\&D activities, we should count an appropriate part, but not all, of the total costs, and some of the costs are hard to apportion appropriately [6].

Chen keming (1987) measured the benefit of agricultural comprehensive research according to crop net output, labor productivity, land productivity, the rate of agricultural products and net income per person [7]. Liu jun (2009) thought lower management level and lacking of efficient allocation of resources is the main reason after analyzing the fact that Chinese agricultural science and technology programs outputs is low [8]. Fan Shenggen (2006) analyzed the impact of Chinese agricultural research investment on urban poverty by establishing simultaneous equations using

\footnotetext{
${ }^{1}$ China statistical yearbook on science and technology
}

time series data [9]. Zhao Zhijun (2005) discussed the main factors that influenced the economic benefit of agricultural R\&D and put forward measure method----extensible CD function. It is concluded that the total benefit of China agricultural R\&D has continued to increase per year, but the marginal rate of return has decreased slowly after 1998 [10]. $\mathrm{Hu}$ Ruifa (2007) thought the proportion of the government competitive funds about agricultural R\&D programs was too high, so that the Strategic long-term planning was limited and the benefit of agricultural R\&D programs could not improve rapidly [5]. Peng yuwen (2007) put forward that promoting achievements in agricultural R\&D programs into practical productive forces was effective measures to increase agricultural research efficiency. It would stimulate enthusiasm to agricultural R\&D investment [11].

Based on the above discussion, it is clear that the benefits of agricultural science and technology programs reflected in a number of aspects, in which the core content are promoting agricultural economic growth or improving farmers' living standards. The impact depends on the inputs of research and development, management methods, agricultural production conditions and farmer's human capital and other factors.

\section{B. The Factors Analysis of Impacting Benefit of Agricultural Science and Technology Programs}

Zhao Zhijin (2005)'s empirical analysis about China's agricultural research investment(1994-2003) suggested that China's agricultural research investment and its total benefit has been on a rising trend, but marginal revenue has been on a declining trend after the maximum value in 1998. The benefit of agricultural research investment has related to research management, agricultural production conditions and economic development [10]. Then, it is a problem to be solved that which factors impacted agricultural research investment benefit and how to quantify and measure the factors.

\section{1) Impact of research management on the benefit of agricultural research investment programs}

According to the characteristics of Chinese agricultural research investment, the government is the main investor. It is different from other countries, China government funds in agricultural research has made contributions greatly to agricultural economy. Then, it is worthy of paying attention that whether the agricultural research funds is sufficient and how the government investment has affected the benefit of agricultural research programs in view of the situation of China's agricultural research investment. In addition, it is much important to know how the funds to be used because the distribution methods of investment funds also affect the benefit of agricultural research programs. So we can discuss the effect from the source and use of investment funds.

In agricultural research programs, the talents who have engaged in agricultural research of science and technology play significant roles. The endogenous growth theory shows human capital has a significant contribution to economic growth and their economic has developed more rapidly than others if the stock of human capital is higher in the regions (Romer, 1986; Lucas, 1986) [12]. Scientific research organization plays an important training role in the economic and social development, while research human capital 
management system and operation mode of organization also determines the efficiency of research investment. Shen Lisheng (1999) and Zhang fan's (2000) study showed that investment in human capital can improve economic growth higher than the investment of material capital [13], [14]. Shen Kunrong (2002) and Hu Yongyuan (2003) found that human capital has a marked positive effect on the economy development [15], [16]. Gao Yuxi (1996) noted the lack of talents and investment in research would make poor areas develop with low efficiency, and the vicious cycle of poverty would appear [17]. Agricultural research investment can make knowledge transform to productivity, so we should stock of science and technology researchers.

\section{2) Impact of agricultural production on the benefit of} agricultural research investment programs

The agricultural production itself will influence the benefits of Agricultural scientific research investment benefit; it can be called agricultural production factors. Li Rui (2006) concluded that the funds allocated R\&D programs which can save land area largely dominated in agricultural public research investment. It is in line with the hypothesis of factor scarcity induced by technology, and until now the research programs that can improve land productivity are easier supported [18]. Song Yanping (2008) summed up planting has been long-term emphasis in China's agricultural research investment by comparing international to China's agricultural research public investment. It was concluded that the government should change ideas to improve the efficiency of China's agricultural research investment by paying more attention to agricultural production structure [19].

Many scholars have been analyzed and selected agricultural production factors that affecting the benefits of agricultural research programs. Li Fang (2003) thought land, fertilizer and power would influence agriculture production value by empirical studying the agricultural research investment in Jiangsu Province [20]. Fan Shenggen (2006) argued that there was relationship between agricultural research and agricultural production, and the factors concluded cultivated land, labor, fertilizer and agricultural machinery [9].

It will be discussed that the factors which affect the benefits of agricultural research programs on the basis of the above academic research achievements. The specific indicators would come from capital investment and usage, the number of researchers and agricultural sources and production conditions.

Government investment to research institution. It comes from directly related department of government. It exist the biggest influence that the government investment to agricultural economic development.

The number of researchers. Human capital becomes one of the most important resources because scientific research technology needs innovation. The researchers who have innovation will play a decisive role in agricultural research programs. So the number of agricultural researchers can be used to explain the changes in agricultural investment efficiency.

Business expenses of research institution. It is actual consumption expenditure in scientific research and technology development activities, such as the expenditure of raw materials for research and developments, water and electricity, travel, processing and testing, equipment, computer machine, printing, as well as the running expenses of training graduate students.

Transformation fund of agricultural science and technology achievements. It is necessary that the government help to spread the agricultural scientific and technological achievements. The support of government can promote the farmers to accept new technology and used it actively. If there is not a good policy environment, it is difficult to complete the transformation of agricultural scientific and technological achievements.

Human capital of farmers. The farmers are the main adopters of agricultural science and technology achievements, and whose quality decides the application of scientific and technological achievements. Chinese farmers are in relatively low level to scientific and technological knowledge due to the environmental constraints of history and reality. In addition, the farmers are not sensitive to market economy and science and technology, which have hindered them to accept the new agricultural technology.

The mechanical power of unit sown area. It can measure the number of inputting agricultural machinery power. The level of using agricultural machine can be reflected by agricultural mechanization.

Effective irrigation area to total crops sown. Irrigation techniques reflect the results of identification of agricultural science and technology research projects in irrigation.

The amount of fertilizer of unit sown area. It can measure the number of using fertilizer during agricultural production. The kinds and usage of fertilizer can show innovation of agricultural science and technology.

\section{PRincipal COMPONENTS ANALYSIS OF FACTORS TO THE Benefit of Agricultural Research Programs}

\section{A. Methodology}

Principal component analysis (PCA) supplies one of the most efficient methods to derive the most important components or factors affecting the regional differences of the social and economic environment. As one of the multivariate statistical technique, PCA is able to analyze the dependencies existing among a set of inter-correlated variables. PCA is conducted on centered data or anomalies, and it is used to identify patterns of simultaneous variation. Its purpose is to reduce a data set containing a large number of inter-correlated variables to a data set containing fewer hypothetical and uncorrelated components, which nevertheless represent a large fraction of the variability contained in the original data. These components are simply linear combinations of the original variables with coefficients given by the eigenvector. A property of the components is that each contributes to the total explained variance of the original variables. The analysis scheme requires that the component contributions occur in descending order of magnitude, such that the largest amount of variance of the first component explains the largest amount of variance of 
the first component explains the largest amount of variance of the original variables, the second explains the next largest, and so on [21].

This paper focuses on the information of Chinese agricultural investment program, such as the number of researchers, agricultural research investment of government, expenditures of research institution, and the data of agricultural production. The data is done using Eviews software with PCA.

TABLE I: THE DATA OF CHINA'S AGRICULTURAL SCIENTIFIC RESEARCH MANAGEMENT AND PRODUCTION INPUT

\begin{tabular}{|c|c|c|c|c|c|c|c|c|}
\hline Year & $\begin{array}{l}\text { The number of } \\
\text { researchers } \\
\text { (person) }\end{array}$ & $\begin{array}{c}\text { Investment of } \\
\text { government } \\
\text { (Ten Thousand } \\
\text { yuan) }\end{array}$ & $\begin{array}{c}\text { Expenditures of research } \\
\text { institution } \\
\text { (Ten thousand yuan) }\end{array}$ & $\begin{array}{l}\text { Farms Human } \\
\text { capital } \\
(\%)\end{array}$ & $\begin{array}{l}\text { Transformation } \\
\text { fund of } \\
\text { technology } \\
\text { (Ten thousand } \\
\text { Yuan) }\end{array}$ & $\begin{array}{l}\text { The mechanical } \\
\text { power per person } \\
\text { (Watt / person) }\end{array}$ & $\begin{array}{c}\text { Proportion of } \\
\text { Effective } \\
\text { Irrigation area } \\
(\%)\end{array}$ & $\begin{array}{l}\text { the amount } \\
\text { of fertilizer } \\
\text { (kilo) }\end{array}$ \\
\hline 2001 & 19896 & 69263 & 108791 & 14.33 & 40000 & 693.4379 & 34.84 & 4253.8 \\
\hline 2002 & 21272 & 96650 & 106792 & 14.42 & 20000 & 740.4046 & 35.15 & 4339.4 \\
\hline 2003 & 21482 & 109743 & 123296 & 14.50 & 20000 & 785.7672 & 35.44 & 4411.6 \\
\hline 2004 & 22346 & 116655 & 152965 & 14.56 & 25000 & 845.75655 & 35.48 & 4636.6 \\
\hline 2005 & 25851 & 141516 & 168265 & 14.83 & 30000 & 917.5520 & 35.39 & 4766.2 \\
\hline 2006 & 26027 & 160679 & 183276 & 14.95 & 30000 & 991.2793 & 36.64 & 4927.7 \\
\hline 2007 & 28066 & 201086 & 232544 & 15.09 & 30000 & 1071.2487 & 36.83 & 5107.8 \\
\hline 2008 & 30223 & 255310 & 306578 & 15.21 & 30000 & 1167.4881 & 37.41 & 5239 \\
\hline 2009 & 25623 & 187440 & 434345 & 15.35 & 40000 & 1269.1984 & 37.35 & 5404.4 \\
\hline
\end{tabular}

Sources: China statistical yearbook on science and technology and China Rural statistical yearbook

\section{B. Data and Methodology}

\section{1) Normalization of original data}

The correlation matrix between variables was calculated after the original data had normalized. It showed the variables were inter-correlated according by the correlation matrix, so it was necessary to do PCA.

\section{2) Calculating eigenvalues, eigenvectors and accumulative variance proportion}

The bottom level of the proportion of the variability of the data explained by the selected principal components was around $70 \%-90 \%$. In our case study, the level of the proportion of the variability was up to $97.79 \%$. By calculating the factor loading matrix after abstraction of principle components, we generated the factor loading matrix identifying the relationship of variance and primary factor. Factor loading is the correlation coefficient between factor and variance.

TABLE II: EIGENVALUES AND ACCUMULATIVE VARIANCE PROPORTION

\begin{tabular}{|c|c|c|c|c|c|}
\hline Number & Value & $\begin{array}{c}\text { Differe } \\
\text { nce }\end{array}$ & Proportion & $\begin{array}{c}\text { Cumulative } \\
\text { Value }\end{array}$ & $\begin{array}{c}\text { Cumulative } \\
\text { Proportion }\end{array}$ \\
\hline 1 & 5.579881 & 3.881901 & 0.6975 & 5.579881 & 0.6975 \\
\hline 2 & 1.697981 & 1.152362 & 0.2122 & 7.277862 & 0.9097 \\
\hline 3 & 0.545618 & 0.44182 & 0.0682 & 7.82348 & 0.9779 \\
\hline 4 & 0.103799 & 0.0571 & 0.013 & 7.927279 & 0.9909 \\
\hline 5 & 0.046698 & 0.021381 & 0.0058 & 7.973977 & 0.9967 \\
\hline 6 & 0.025317 & 0.024747 & 0.0032 & 7.999294 & 0.9999 \\
\hline 7 & 0.00057 & 0.000435 & 0.0001 & 7.999864 & 1 \\
\hline 8 & 0.000136 & --- & 0 & 8 & 1 \\
\hline
\end{tabular}

\section{3) Explanation of principal components}

Based on the PCA, three components were derived from the very detailed indicators. The weights of famers' human capital, agricultural machine, fertilizer on the principal component I were the highest. The principal component I mainly reflected the agricultural production conditions, which shows agricultural production activities plays a significant role in the application of agricultural scientific and technological achievements. So the principal component I was agricultural production factor. The number of researchers and the funds of government investing owned the biggest weights in principal component II. Therefore, the principal component II mainly represented the investment in human and financial resources. It was the research management factor. The transformation funds of achievements owned the biggest weights in principal component III. So the principal component III mainly represented the technical guidance conditions to farms.

\section{TABLE III: EIGENVECTORS}

\begin{tabular}{|l|c|c|c|}
\hline \multicolumn{1}{|c|}{ variables } & PC1 & PC2 & PC3 \\
\hline The number of researchers (person) & 0.215479 & 0.634213 & 0.310863 \\
\hline $\begin{array}{l}\text { Investment of government } \\
\text { (Ten thousand yuan) }\end{array}$ & 0.318035 & 0.502057 & 0.035464 \\
\hline $\begin{array}{l}\text { Expenditures of research institution } \\
\text { ( Ten thousand yuan ) }\end{array}$ & 0.34582 & -0.365686 & -0.38776 \\
\hline $\begin{array}{l}\text { Farms human capital (\%) } \\
\text { Transformation fund of technology } \\
\text { (Ten thousand yuan ) }\end{array}$ & 0.413395 & -0.065904 & 0.092215 \\
\hline $\begin{array}{l}\text { The mechanical power per person } \\
\text { (Watt /person) }\end{array}$ & 0.27345 & -0.416023 & 0.693405 \\
\hline $\begin{array}{l}\text { Proportion of Effective irrigation } \\
\text { area(\%) }\end{array}$ & 0.377105 & 0.126987 & -0.49734 \\
\hline the amount of fertilizer (kilo) & 0.413421 & -0.065732 & 0.103912 \\
\hline
\end{tabular}


4) Calculating the score of each principal component and comprehensive benefits

According to the formula: $Z=0.6975$ PCI +0.2122 PCII $+0.0682 \mathrm{PCIII}$

TABLE IV: COMPREHENSIVE BENEFITS

\begin{tabular}{|r|r|r|r|r|}
\hline year & PCI & PCII & PCIII & $\begin{array}{c}\text { Comprehensive } \\
\text { benefits }\end{array}$ \\
\hline 2001 & 3.471976815 & 0.446124731 & 0.700265081 & 2.56413 \\
\hline 2002 & 2.791439555 & 0.036004848 & 0.571436122 & 1.993641 \\
\hline 2003 & 2.293340791 & -0.043713681 & 0.726056805 & 1.639846 \\
\hline 2004 & 1.477965057 & 0.204184448 & 0.239889477 & 1.090569 \\
\hline 2005 & 0.602158833 & 0.220396894 & -0.275969113 & 0.447953 \\
\hline 2006 & 0.864526217 & 0.27810256 & -0.107241885 & 0.654707 \\
\hline 2007 & 1.828157467 & 0.878653241 & 0.018153656 & 1.462828 \\
\hline 2008 & 3.184046523 & 1.463626715 & -0.28440251 & 2.512058 \\
\hline 2009 & 3.827085585 & -1.084722959 & -0.167128627 & 2.427816 \\
\hline
\end{tabular}

\section{CONCLUSION AND DISCUSSION}

It was showed the benefits of Chinese agricultural science and technology programs were a U-shaped curve from 2001 to 2009. The benefit began showing a downward trend from 2001 to 2005, and then it gradually increases from 2006 to 2007. There were many reasons to explain the diminishing composite score from 2001 to 2005. First, the transformation funds of achievements were highest in 2001, which was two twice the latter three years. Beginning in 2007, the funds began to significantly increase, which promoted the benefit of agricultural science and technology projects. Second, the ratio of government investment and total value of agricultural production showed a downward trend although government research investment was increasing per year. This was an important factor affecting the benefit of agricultural research projects.

By analyzing the factor to the benefit of agricultural research programs, we found that the direct input of the countries on research projects (both human and financial) plays an important role. The number of researchers and investment generated positive impact to the benefit of agriculture research. Of course, the factors of regional economic development and production technology also affect the benefits of scientific and technological projects. We should also give some attention to them.

\section{REFERENCES}

[1] S. G. Fan, "Research Investment and the Economic Returns to Chinese Agricultural Research," Journal of Productivity Analysis, vol. 14, pp. 163-182, 2000

[2] R. Evenson, "Economic Impact of Agricultural Research and Extension," Handbook of Agricultural Economics, Jan. 2000.

[3] R. R. Hu, J. K Huang, and X. D. Fang, "Analyzing the total quantity of agricultural research investment," Management for Economy in Agricultural Scientific Research, vol. 3, pp. 21-24, July, 1998.

[4] J. K. Huang and R. F. Hu, "Chinese agricultural research investment: benefit, distribution of benefits and policy implication," China Soft Science, vol. 9, pp. 95-100, Sep. 2000.
[5] R. F. Hu, K. Y. Shi, and Y. W. Yong, "Change in China's Agricultural Research Investment and Its International Comparison," China Soft Science, vol. 2, pp. 53-65, Feb. 2007.

[6] J. M. Alston and P. G. Pardey, "Attribution and other problems in assessing the returns to agricultural R\&D," Agricultural Economics, vol. 25 , pp. 141-152, 2001 .

[7] K. M. Chen, "Evaluation system of agricultural comprehensive research achievements," Science Research Management, vol. 1, pp. 43-47, Jan. 2008.

[8] J. Liu, Y. Zhai, and W. L. Wang, "Thinking about improving investment benefit of agricultural scientific and technological project," Management for Economy in Agricultural Scientific Research, vol. 3, pp. 12-17, June 2009.

[9] S. G. Fan, P. Xing, C. Fang et al., "Agricultural Research and town poverty," Journal of Agrotechnical Economics, vol.5, pp. 9-15, Sep. 2006 (in Chinese).

[10] Z. J. Zhao and S. M. Zhang, "Analysis of macro-economic benefits of China's Agricultural Research Investment," Journal of Agrotechnical Economics, vol. 6, pp. 41-47, Nov. 2005.

[11] Y. W. Peng and L. H. Wu, "China-US agricultural science and technology funding comparisons and Countermeasures," Forum on Science and Technology in China, vol. 12, pp. 89-92, Dec. 2007.

[12] R. E. Lucas, "On the Mechanics of Economics Development," Journal of Monetary Economics, vol. 22, pp. 3-42, 1986.

[13] L. H. Shen and Y. F. Zhu, Analysis of Human Capital and Economic Growth, Social sciences documentation publishing house, 1999

[14] F. Zhang, "Evaluation of China's human capital and material capital." Economic Research, pp. 65-71, Aug. 2000.

[15] K. R. Shen and J. Ma, "The Characteristics of 'Club Convergence' of China's Economic Growth and Its Cause," Economic Research, vol. 1, pp. 33-39, Jan. 2002.

[16] Y. Y. Hu, "Human capital and economic growth," Economic Science, vol. 1, pp. 54-60, Jan. 2003.

[17] Y. X. Gao, "Human capital investment and economic growth in China poor areas," Management World, pp. 189-197, Sep. 1996.

[18] R. Li and Z. N. Li, "China's Agricultural Research Investment Efficiency," Journal of Management Sciences in China, vol. 10, pp. 81-88, Aug. 2007.

[19] Y. P. Song and C. X. Zhang, "Thinking about how to Improve the Efficiency of China's Agricultural Research Investment," Science and Technology Progress and Policy, Jan. 2008.

[20] F. Li and J. H. Zhang, "Analysis of Jiangsu province's agricultural research investment," Science \& Technology and Economy, vol. 16, pp. 39-41, Aug. 2003

[21] P. Wang and B. Z. Zhu, "Comprehensive Evaluation of the Enterprise Independent Innovation Project Based on Principal Component Analysis," Journal of WUT (Information and management Engineering), vol. 30, no. 6, pp. 987-990, Dec. 2008.

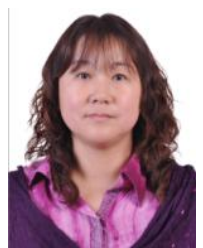

Chunmei Wang was born in Bao Tou, Inner Mongolia, China; Birth date: March 16, 1976. Education: 2011-now, Doctor Candidate of management science and engineering, College of Economics and Management, China Agricultural University, Beijing, P.R. China; 2004, Master degree of management science and Engineering, School of Management, Inner Mongolia University of Technology, Hohhot, Inner Mongolia P.R. China; 2001, Bachelor degree of Chemistry, Chemistry department, Inner Mongolia Normal University, Hohhot, Inner Mongolia P.R. China. From 2004 to now, I have worked in College of accounting, Inner Mongolia University of Finance and Economics, Hohhot, P.R. China. There were some publications, such as: the effects of accounting information system to financial management modes (Communication of finance and accounting, July. 2012), Research on internal control module procurement under the environment of ERP (China management information, Feb. 2013), etc. Previous research interest is theory and practice of ERP, and current interest project evaluation. 